\title{
STRAIN-CONCENTRATION FACTOR OF INTERNALLY PRESSURIZED THICK-WALLED CYLINDERS
}

\author{
H.M. TLILAN*, A.M. JAWARNEH, A. ABABNEH, M. TARAWNEH and M. RABABAH \\ Department of Mechanical Engineering, Faculty of Engineering \\ The Hashemite University (HU), Zarqa, 13115, JORDAN
}

O.A. SMADI

Department of Bio-Medical Engineering, Faculty of Engineering

The Hashemite University (HU), Zarqa, 13115, JORDAN

\begin{abstract}
This study introduces a new definition of the strain-concentration factor (SNCF) of thick walled internally pressurized cylinders. The stress state has been considered in this new definition; i.e. triaxial and biaxial stress states for closed and open ends, respectively. Primarily, the curvature effect of the strain concentration has been studied here. To this end, the inner radius of the employed cylinders has been changed from 0.5 to $50.8 \mathrm{~mm}$. On the other hand, the thickness has been kept constant at $16.7 \mathrm{~mm}$. Moreover, the thickness has been fragmented to 37 elements to study the thickness effect for each case. The results show that the tangential (hoop) strain regularly spread over the whole thickness. It has been revealed that the maximum value of the tangential strain occurs on the inner surface of the cylinder. In particular, it rapidly decreases from a maximum value on the inner surface to reach its minimum value on the outer surface, which is nearly equal to the average value of hoop strain through the thickness. The results also demonstrate that tangential strain values decrease with the increase of the inner radius for any thickness. It is clear that the rate of decrease of the hoop strain changes abruptly with decreasing the inner radius of the cylinder. This led to localization of the strain concentration on the inner surface of the cylinder due to curvature, making the values of the strain concentration factor very high on the inner surface of the cylinder. In addition, the strain concentration factor decreases through the thickness of the cylinder from the inner to outer surfaces, and the rate of the decrease is increasing with a decreasing inner radius of the cylinder. The current results introduce the serious effect of the curvature on the strain concentration even if there are no irregularities in the cylinder.
\end{abstract}

Key words: vessels, stress, strain, strain concentration.

\section{Introduction}

The issue of pressurized thick-walled cylinders under elastic, elastic-plastic and plastic deformation is very important for industrial applications. It is well-known that the primary purpose of any industry is to provide secure and reliable efficient application without any source of failure. The use of pressurized vessels such as nuclear, refineries, pipelines and any other types of container with fluid under pressure is one of the critical industrial applications. The through thickness stress and strain distributions are the main source of failure of the internally, externally pressurized vessels. In the literature, the problem of characterizing the stress distribution of the pressurized thick-walled cylinder has been extensively studied. An exact solution for elastic perfectly plastic internally pressurized thick-walled cylinders was introduced by Hill [1] and Nadai [2]. Thick vessels have been studied analytically and FEA was used by many researchers [3-12]. In addition to that, many researchers have studied this issue numerically [13-16]. It has been deduced by all of

\footnotetext{
* To whom correspondence should be addressed
} 
the above researchers that the stress distribution throughout the thickness is strongly affected by material, geometrical properties and end conditions.

Most of the published studies have focused on the stress concentration of the pressurized vessels. This issue has been studied using many techniques such as, exact solution [1, 2]; FEM [8-12, 17-21], analytical solutions [1-5, 22-25], and numerically [13-16]. It has also been investigated experimentally by Kaufman [3]. The majority of the above studies focus on the material and geometrical properties causing strain concentrations. Specifically, the stress concentration considered is introduced by the irregularities on the wall thickness. The effects of end conditions on the stress - concentration factor have also been studied and reviewed. It has been deduced that the stress concentration of pressurized vessels either thick or thin is very imperative and should be extensively studied [26, 27].

Unfortunately, the strain concentration has not been extensively studied for thick-walled cylinders. Even the curvature effect on the strain concentration factor has not been studied. To this end; the strainconcentration factor for thick walled cylinders is studied in this paper. The curvature effect on strain concentration factor is introduced here.

\section{Stress-strain relations for internally pressurized thick-walled cylinders}

We refer to the basics of the tangential and radial stresses for thick walled cylinders, which are wellstudied and used in the engineering design

$$
\begin{aligned}
& \sigma_{\theta}=\frac{P_{i} r_{i}^{2}-P_{o} r_{o}^{2}-r_{i}^{2} r_{o}^{2}\left[\frac{P_{o}-P_{i}}{R^{2}}\right]}{r_{o}^{2}-r_{i}^{2}} ; \quad r_{i} \leq R \leq r_{o}, \\
& \sigma_{r}=\frac{P_{i} r_{i}^{2}-P_{o} r_{o}^{2}+r_{i}^{2} r_{o}^{2}\left[\frac{P_{o}-P_{i}}{R^{2}}\right]}{r_{o}^{2}-r_{i}^{2}} .
\end{aligned}
$$

If the cylinder has closed ends; the longitudinal stress will be introduced and it has a constant value throughout the thickness. It is obtained as follows

$$
\sigma_{z}=\frac{P_{i} r_{i}^{2}-P_{o} r_{o}^{2}}{r_{o}^{2}-r_{i}^{2}}
$$

For internally pressurized thick walled cylinders, i.e. $P_{\mathrm{o}}=0.0$, Eqs (2.1)-(2.3) can be transformed to

$$
\begin{aligned}
& \left(\sigma_{\theta}\right)_{i}=P_{i} \frac{r_{i}^{2}}{R^{2}}\left(\frac{r_{o}^{2}+R^{2}}{r_{o}^{2}-r_{i}^{2}}\right) \\
& \left(\sigma_{r}\right)_{i}=-P_{i}, \text { at the inner radius } \\
& \left(\sigma_{r}\right)_{o}=0.0 .
\end{aligned}
$$

If the cylinder has closed ends; then the longitudinal stress is given by 


$$
\sigma_{z}=P_{i}\left(\frac{r_{i}^{2}}{r_{o}^{2}-r_{i}^{2}}\right)
$$

For elastic deformation and using the generalized Hook's law; the tangential strain $\left(\varepsilon_{\theta}\right)$ has the following form

$$
\left(\varepsilon_{\theta}\right)=\left\{\begin{array}{l}
\frac{1}{\mathrm{E}}\left\{\left(\sigma_{\theta}\right)-v\left[\left(\sigma_{r}\right)+\left(\sigma_{z}\right)\right]\right\}=\frac{r_{i}^{2} P_{i}}{\mathrm{E}\left(r_{o}^{2}-r_{i}^{2}\right)}\left[(1-2 v)+\frac{r_{o}^{2}}{R^{2}}(1+v)\right], \text { for closed ends cylider, } \\
\frac{1}{\mathrm{E}}\left[\left(\sigma_{\theta}\right)-v\left(\sigma_{r}\right)\right]=\frac{r_{i}^{2} P_{i}}{\mathrm{E}\left(r_{o}^{2}-r_{i}^{2}\right)}\left[(1-v)+\frac{r_{o}^{2}}{R^{2}}(1+v)\right], \text { for open ends cylider, i.e. } \sigma_{z}=0.0 .
\end{array}\right.
$$

Equation (3.1) indicates that $\left(\varepsilon_{\theta}\right)$ occurs under triaxial stress state for closed ends cylinders, whereas it occurs under biaxial stress state for open ends cylinders. It should be noted that the maximum tangential strain $\left(\varepsilon_{\theta}\right)_{\max }$ occurs at the inner surface, i.e. $r=r_{i}$, of the cylinder. As a result, for closed ends cylinders Eq.(3.1) leads to

$$
\left(\varepsilon_{\theta}\right)_{\max }=\frac{r_{i}^{2} P_{i}}{\mathrm{E}\left(r_{o}^{2}-r_{i}^{2}\right)}\left[(1-2 v)+\frac{r_{o}^{2}}{r_{i}^{2}}(1+v)\right]=\frac{P_{i}}{\mathrm{E}\left(r_{o}^{2}-r_{i}^{2}\right)}\left[r_{i}^{2}(1-2 v)+r_{o}^{2}(1+v)\right],
$$

and for open ends cylinders; $\sigma_{z}=0.0$

$$
\left(\varepsilon_{\theta}\right)_{\max }=\frac{r_{i}^{2} P_{i}}{\mathrm{E}\left(r_{o}^{2}-r_{i}^{2}\right)}\left[(1-v)+\frac{r_{o}^{2}}{R^{2}}(1+v)\right]=\frac{P_{i}}{\mathrm{E}\left(r_{o}^{2}-r_{i}^{2}\right)}\left[r_{i}^{2}(1-v)+r_{o}^{2}(1+v)\right] .
$$

\section{New strain - concentration factor internally pressurized thick-walled cylinders}

For internally pressurized thick-walled cylinders, a new definition of the strain concentration factor $K_{e}{ }^{*}$ is introduced. The factor $K_{e}{ }^{*}$ is defined as the ratio of the maximum tangential (hoop) strain $\left(\varepsilon_{\theta}\right)_{\max }$ to the new average tangential strain $\left(\varepsilon_{\theta}\right)_{a v}^{*}$. Since the maximum tangential (hoop) strain always occurs at the inner surface; therefore, it is independent of definition. In addition, Eqs (2.8) and (2.9) clarify that $\left(\varepsilon_{\theta}\right)_{\max }$ occurs under triaxial and biaxial stress state for closed and open ends cylinders, respectively. As a result, the new $K_{\varepsilon}^{*}$ is introduced by a new definition of the $\left(\varepsilon_{\theta}\right)_{a v}^{*}$ on the gross and net section thicknesses as follows

$$
K_{\varepsilon}^{*}=\frac{\left(\varepsilon_{\theta}\right)_{\max }}{\left(\varepsilon_{\theta}\right)_{\mathrm{av}}^{*}}
$$

The new average tangential strain introduced here is defined under triaxial stress state 


$$
\left(\varepsilon_{\theta}\right)_{\mathrm{av}}^{*}=\frac{1}{A} \int_{A} \varepsilon_{\theta} d A=\frac{1}{\pi\left(r_{o}^{2}-r_{i}^{2}\right)} \int_{R}^{r_{o}} \varepsilon_{\theta}(R) 2 \pi R d R
$$

For elastic deformation Eq.(3.2) can be rewritten as

$$
\left(\varepsilon_{\theta}\right)_{\mathrm{av}}^{*}= \begin{cases}\frac{1}{\mathrm{E} A} \int_{A}\left\{\left(\sigma_{\theta}\right)-v\left[\left(\sigma_{r}\right)+\left(\sigma_{z}\right)\right]\right\} d A=\frac{\left(\sigma_{\theta}\right)_{\mathrm{av}}}{\mathrm{E}}-\frac{v}{\mathrm{E} A} \int_{A}\left[\left(\sigma_{r}\right)+\left(\sigma_{z}\right)\right] d A, & \text { closed ends cylinder, } \\ \frac{1}{\mathrm{E} A} \int_{A}\left[\left(\sigma_{\theta}\right)-v\left(\sigma_{r}\right)\right] d A=\frac{\left(\sigma_{\theta}\right)_{\mathrm{av}}}{\mathrm{E}}-\frac{v}{\mathrm{E} A} \int_{A} \sigma_{r} d A, & \text { open ends cylinder. }\end{cases}
$$

Recalling Eqs (2.7), (2.5) and (2.6); for open ends cylinders Eq.(3.3) becomes

$$
\left(\varepsilon_{\theta}\right)_{\mathrm{av}}^{*}=\frac{P_{i} r_{i}^{2}}{\mathrm{E} \pi\left(r_{o}^{2}-r_{i}^{2}\right)\left(r_{o}^{2}-R^{2}\right)}\left[(1-v)\left(r_{o}^{2}-R^{2}\right)+(2+2 v) r_{o}^{2} \ln \left(\frac{r_{o}}{R}\right)\right] .
$$

On the other hand, $\left(\varepsilon_{\theta}\right)_{a v}^{*}$ for closed ends cylinders has the following form

$$
\left(\varepsilon_{\theta}\right)_{\mathrm{av}}^{*}=\frac{P_{i} r_{i}^{2}}{\mathrm{E} \pi\left(r_{o}^{2}-r_{i}^{2}\right)\left(r_{o}^{2}-R^{2}\right)}\left[(1-2 v)\left(r_{o}^{2}-R^{2}\right)+(2+2 v) r_{o}^{2} \ln \left(\frac{r_{o}}{R}\right)\right] .
$$

For open ends cylinders, substitution of Eqs (2.9) and (3.4) into Eq.(3.1) leads to

$$
\left(K_{\varepsilon}^{*}\right)_{\text {open }}=\frac{\left(r_{o}^{2}-R^{2}\right)\left[(1+v) r_{o}^{2}+(1-v) R^{2}\right]}{R^{2}\left[(1-v)\left(r_{o}^{2}-R^{2}\right)+(2+2 v) r_{o}^{2} \ln \left(\frac{r_{o}}{R}\right)\right]}
$$

whereas for closed ends cylinders

$$
\left(K_{\varepsilon}^{*}\right)_{\mathrm{closed}}=\frac{\left(r_{o}^{2}-R^{2}\right)\left[(1+v) r_{o}^{2}+(1-2 v) R^{2}\right]}{R^{2}\left[(1-2 v)\left(r_{o}^{2}-R^{2}\right)+(2+2 v) r_{o}^{2} \ln \left(\frac{r_{o}}{R}\right)\right]} .
$$
properties.

It is clear from Eqs (3.6) and (3.7) that the SNCF depends only on geometrical and mechanical

\section{Material and geometrical properties}

A thick-walled cylinder of variable inner radius $\left(r_{i}\right)$, outer radius $\left(r_{o}\right)$ and constant wall thickness is subjected to internal pressure $P i$, as shown in Fig.1. Both closed and open ends cylinders are employed in this study. It should be noted that the inner radius of the cylinder has been varied from 0.5 to $50.8 \mathrm{~mm}$ to verify the effect of the curvature of the cylinder on the strain concentration. The cylinder has a constant wall thickness of $16.7 \mathrm{~mm}$ for each radius. An austenitic stainless steel with the elastic modulus $E$ of $206 \mathrm{GPa}$, and Poisson's ratio $v$ of 0.3 has been employed here. 
Due to symmetry; one quarter of the vessel needs to be modeled. As the focus of this analysis is on the response in the vicinity of the thickness, the geometry of the cylinder in Fig.1 was also considered for a thorough numerical analysis of thickness elasticity using MATLAB. The internally pressurized thick-walled cylinder elastic responses were obtained by meshing one-quarter of the specimen four-node elements under open and closed ends assumptions, respectively.

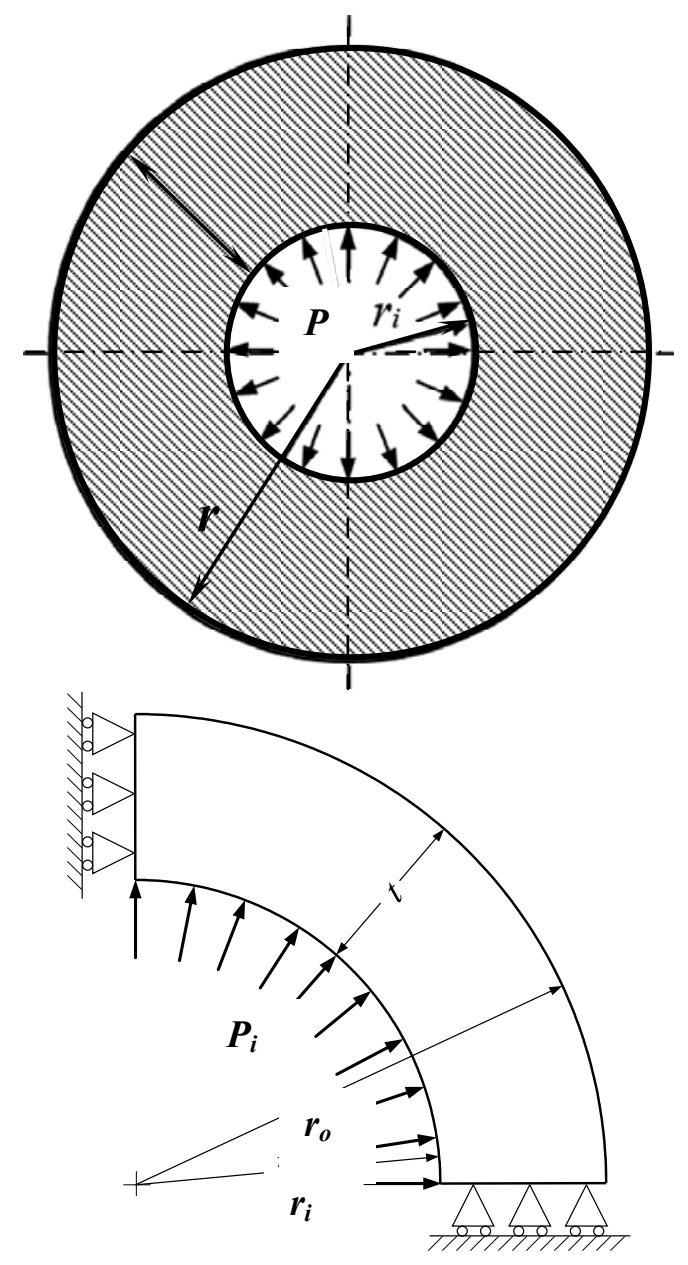

Fig.1. Geometrical properties of the thick-walled cylinder.

\section{Results and discussion}

Strain concentrations in thick - walled cylinders are due to curvature by direct application of an internal pressure on those cylinders. Strain values obtained from MATLAB simulation together with stress values during pressurizing can be used to determine the stress and strain concentration factors introduced by the internal pressure of the thick-walled cylinders. Calculations on the distribution of the elastic tangential $\varepsilon_{\theta}$, radial $\varepsilon_{r}$, and longitudinal $\varepsilon_{z}$ strains for the closed and open ends cylinders reveal that there is a prominent effect of the cylinder curvature on the elastic strains distribution throughout the wall thickness as shown in Figs 2, 3, 4, and 5. It is shown that the maximum $\varepsilon_{\theta}$ and $\varepsilon_{r}$ take place in the highly stressed (pressurized) region, which is the inner surface of the cylinders. Due to the triaxial stress state of closed ends cylinders and biaxial stress state for open ends cylinders, the strain has non-zero finite values at any location from the inner to the outer surfaces. The rate of decrease in the $\varepsilon_{\theta}$ and $\varepsilon_{r}$ values from its maximum at the inner surface increases with decreasing the inner diameter of the cylinder. 


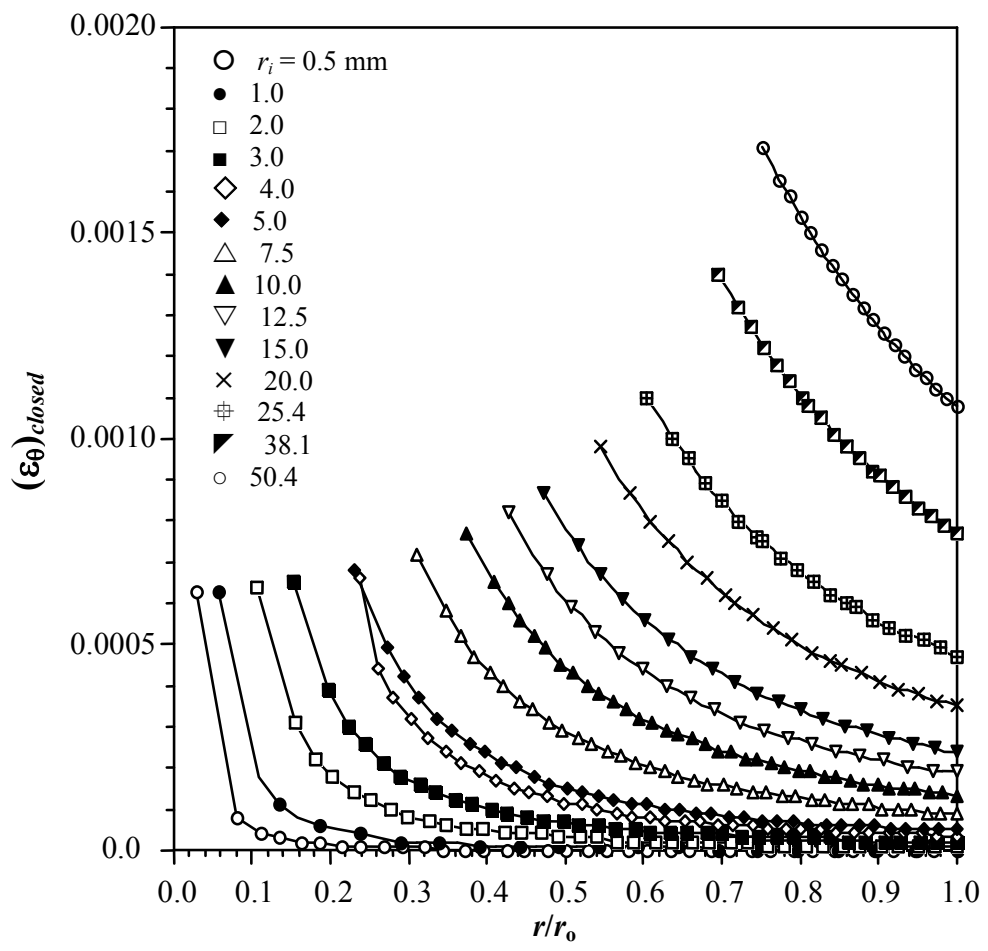

Fig.2. The tangential strain distribution for closed ends thick-walled cylinder.

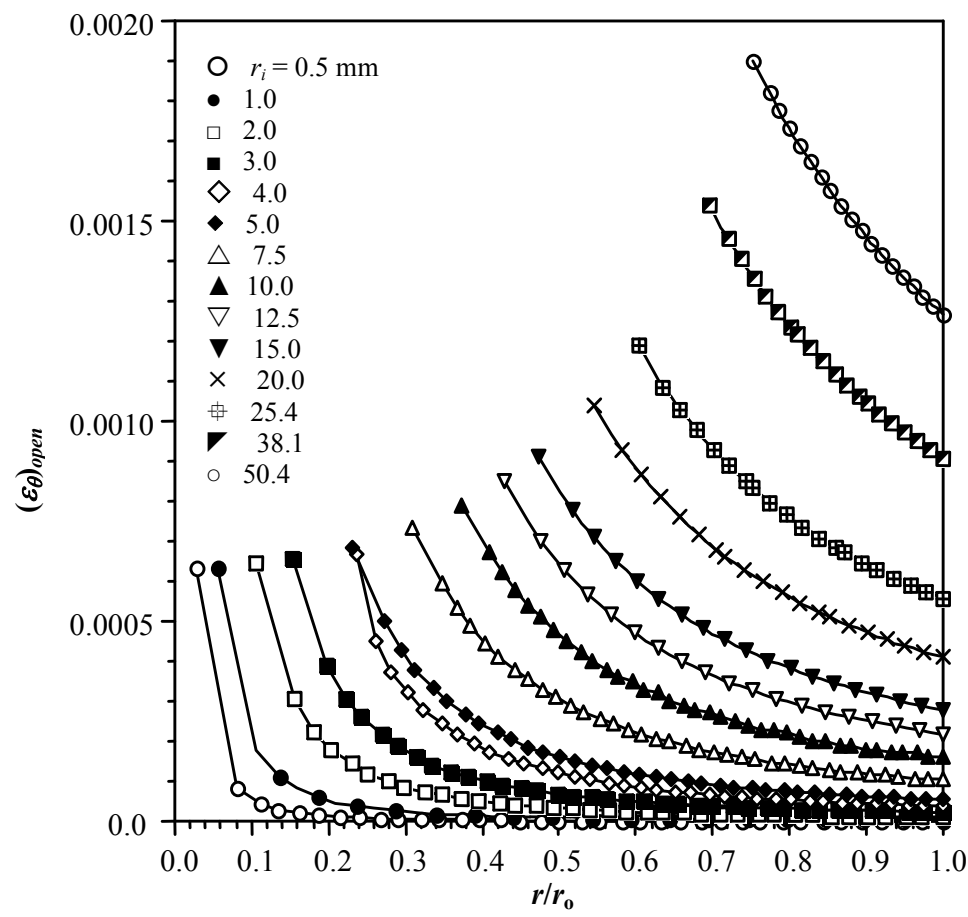

Fig.3. The tangential strain distribution for open ends thick-walled cylinder. 


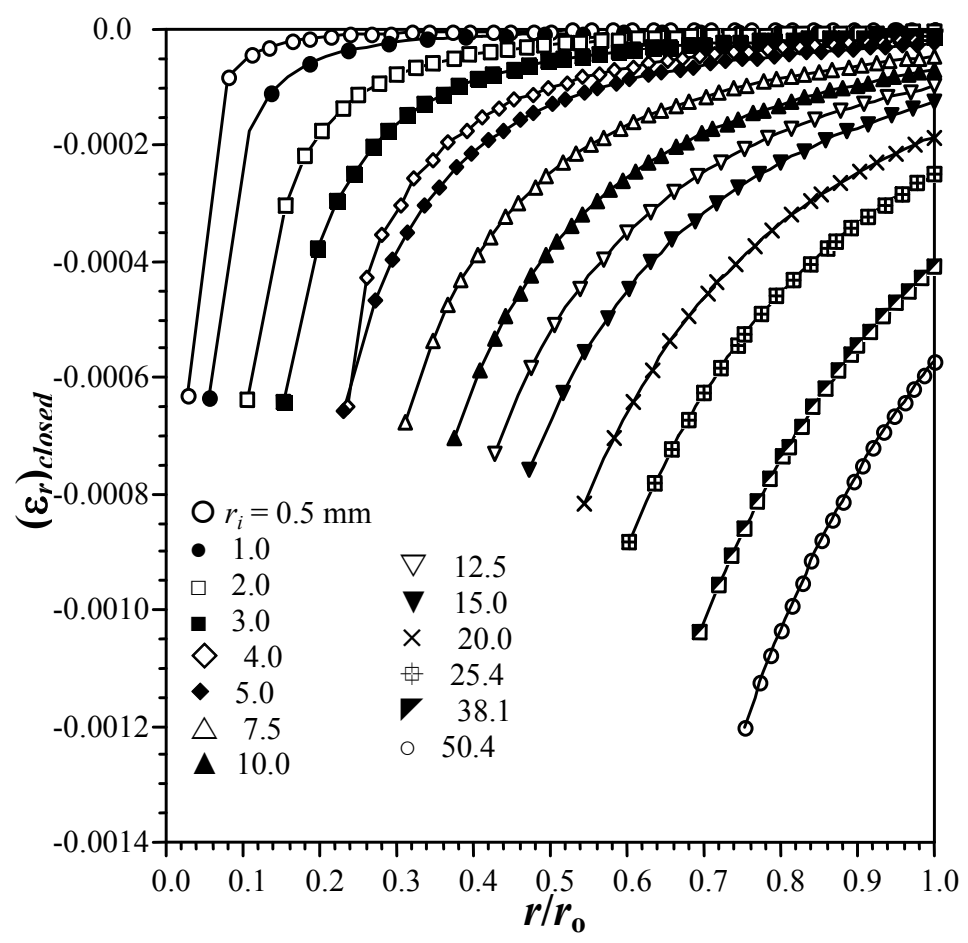

Fig.4. The radial strain distribution for closed ends thick-walled cylinder.

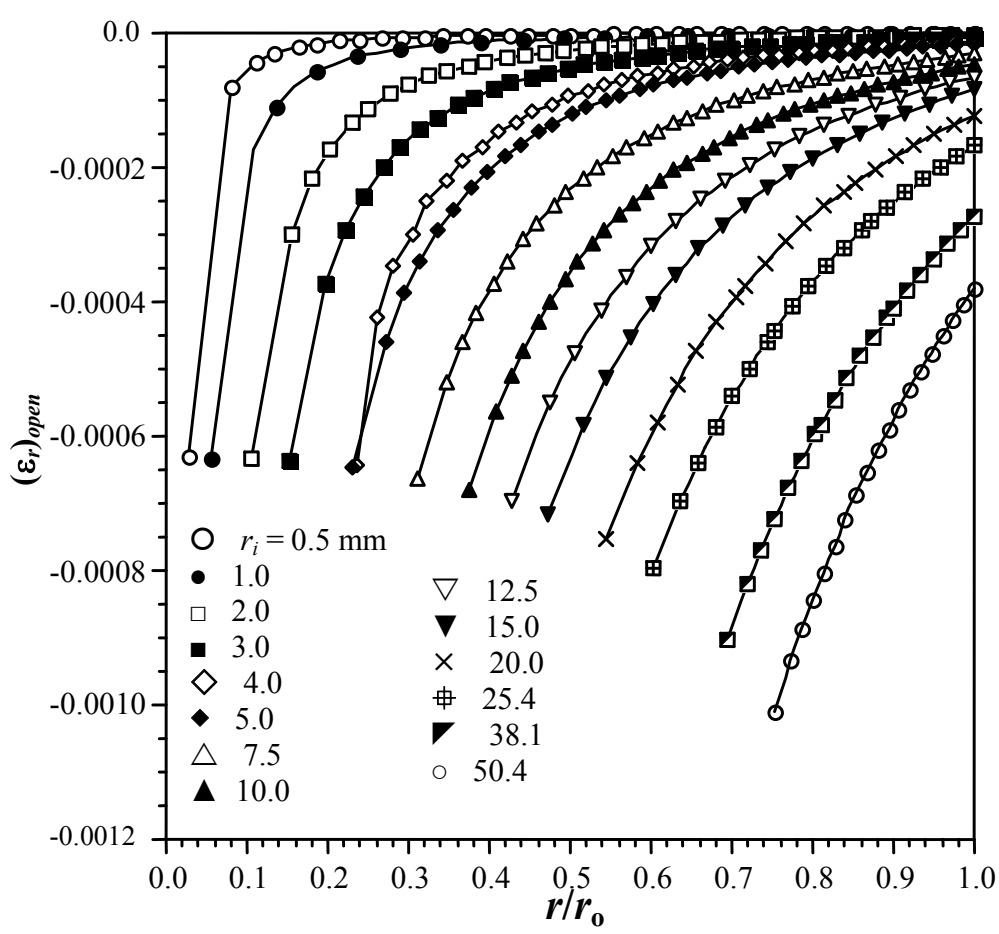

Fig.5. The radial strain distribution for open ends thick-walled cylinder.

The variations of the new strain concentration and stress concentration factors with the inner radius for open and closed ends cylinders are compared in Figs 6-19. For the same thickness, the SNCF decreases 
from its maximum at the inner surface and reaches a minimum value at the outer surface. This is an indication that the SNCF is strongly affected by the curvature of the thick-walled cylinders. This could be clarified using the variation of the SNCF with the wall thickness from the inner to outer radii, as shown in Figs 6 - 19. It is prominent that the SNCF rapidly decreases with increasing thickness; i.e. increasing inner radius, which means increasing of the severity of the curvature.

It should be noted that the stress and strain concentration region is localized at the inner surface for all of the employed cylinders. Moreover, this localization of the stress and strain concentration converges to the inner surface as the inner radius of the cylinder decreases.

To clarify the effect of the thickness of the cylinder on the stress and strain concentration factors, the variations of those factors with thickness are given in Figs 6 - 19. The wall thickness of zero value means that it is at the inner surface of the cylinder. The SNCF and SSCF decrease sharply with increasing thickness for all of the cylinders employed. It is clear that the rate of decrease in the SNCF and SSCF diminishes with increasing the inner radius of the cylinder. This is an important result that the strain concentration is introduce a even if there are no irregularities in the cylinders. This phenomenon should be considered in the design of such structures.

Since the strain concentration has not been studied before; the current result has been compared with the stress concentration results. The curvature effect on stress concentration has been studied by many researches $[26,27]$. They deduced that the stress concentration is strongly affected by the curvature of the vessels. To validate the current study the results have been compared with the previous published results. The strain concentration is strongly affected by the curvature and the values of the strain concentration factor are greater than those of the stress concentration factor. The difference between the SNCF and SSCF values increases with increasing the inner radius of the cylinders.

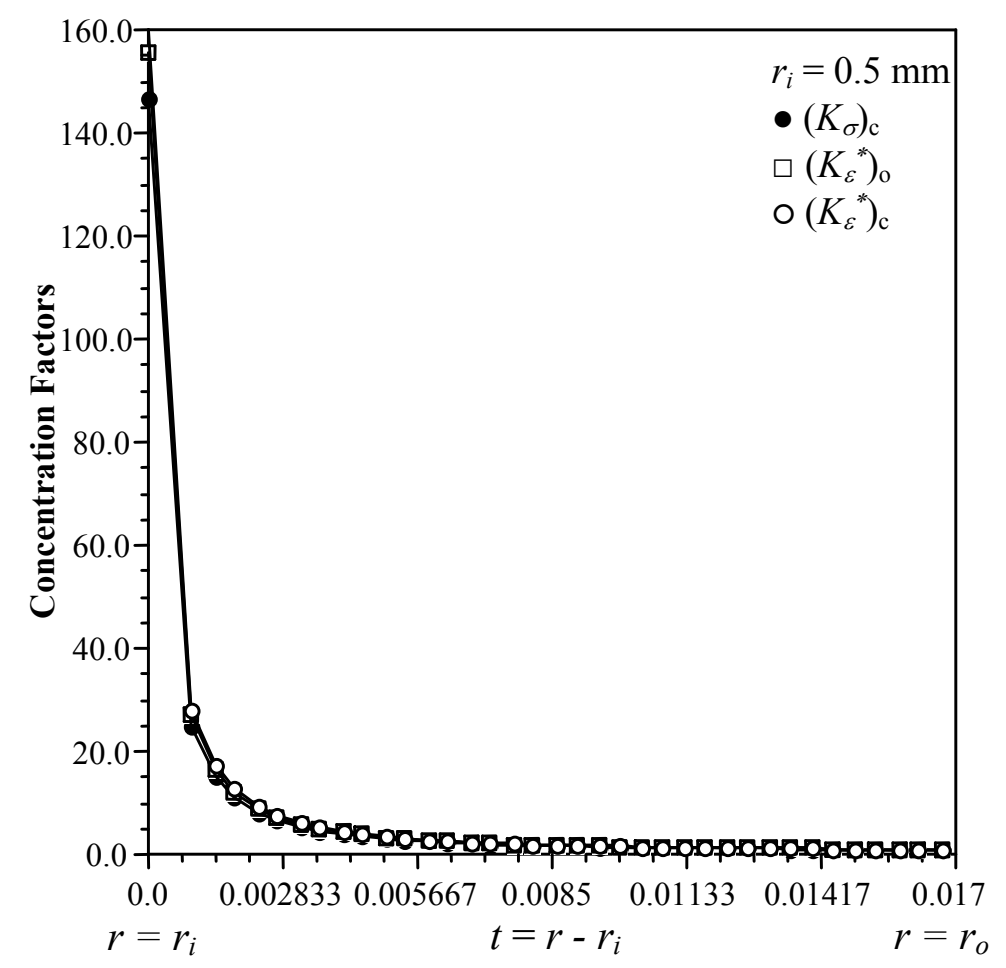

Fig.6. The variation of concentration factors with thickness for $r_{i}=0.5 \mathrm{~mm}$. 


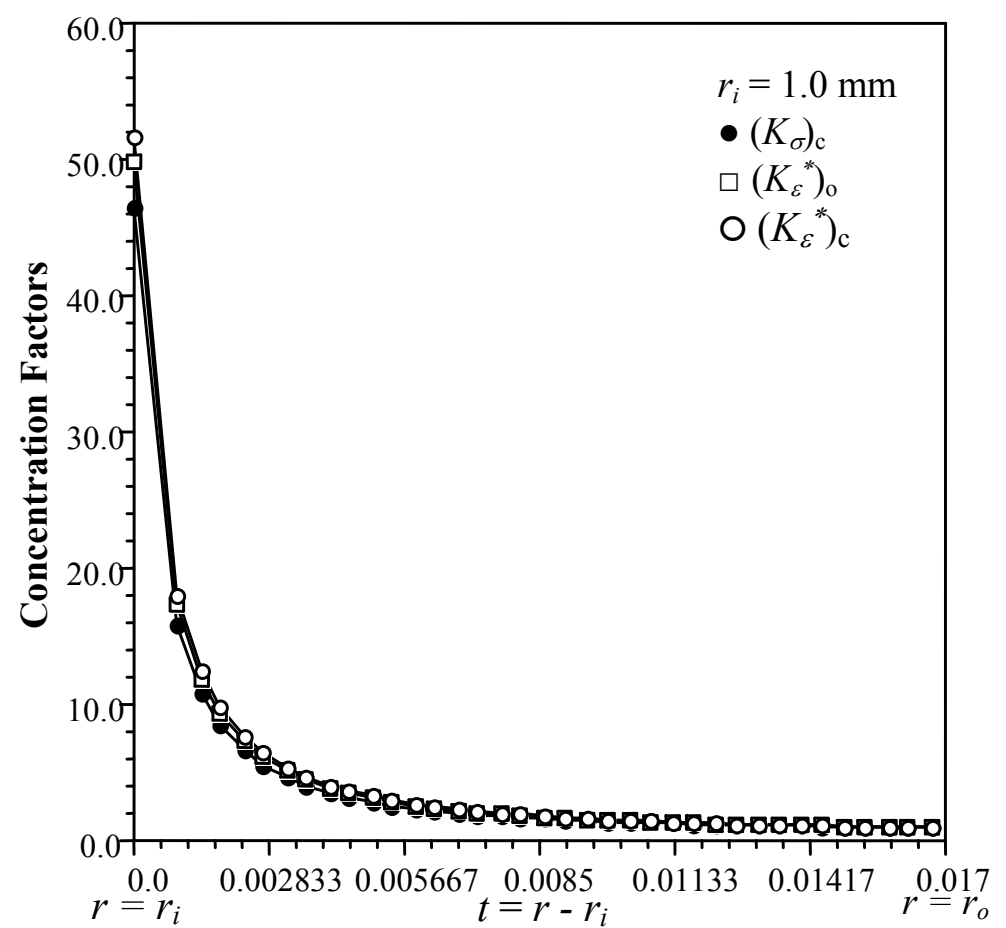

Fig.7. The variation of concentration factors with thickness for $r_{i}=1.0 \mathrm{~mm}$.

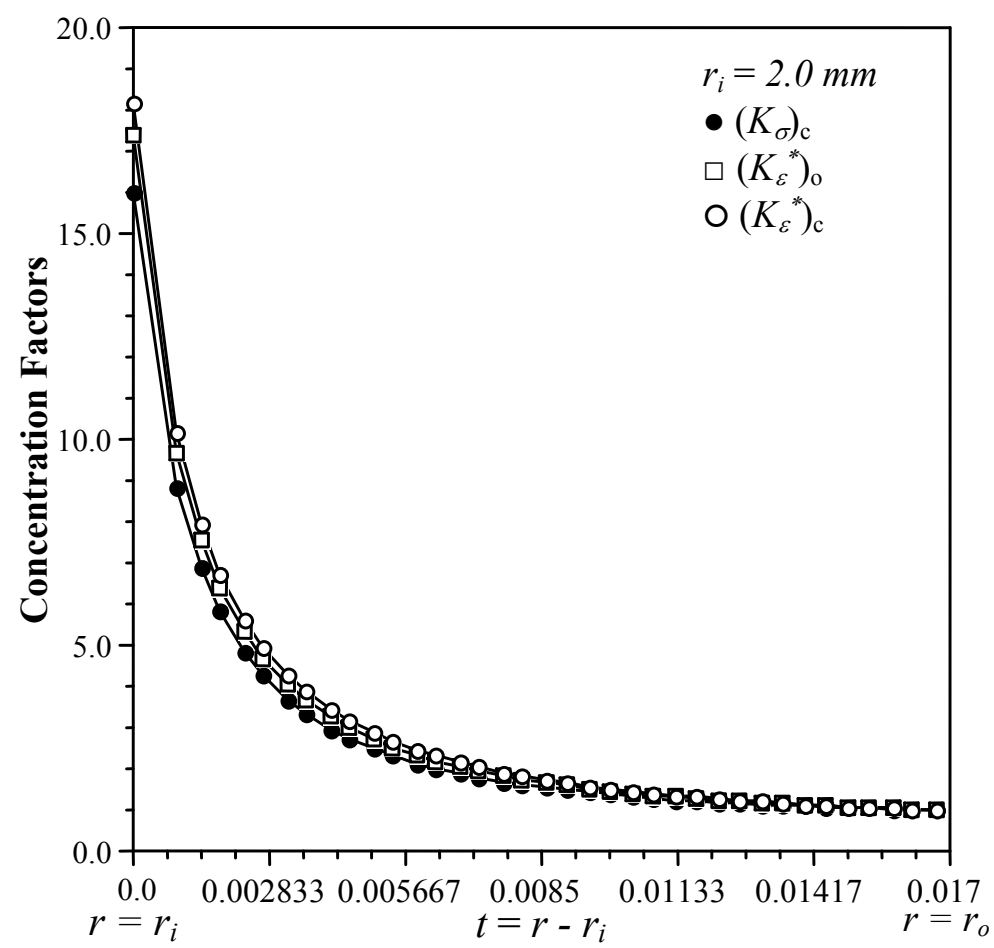

Fig.8. The variation of concentration factors with thickness for $r_{i}=2.0 \mathrm{~mm}$. 


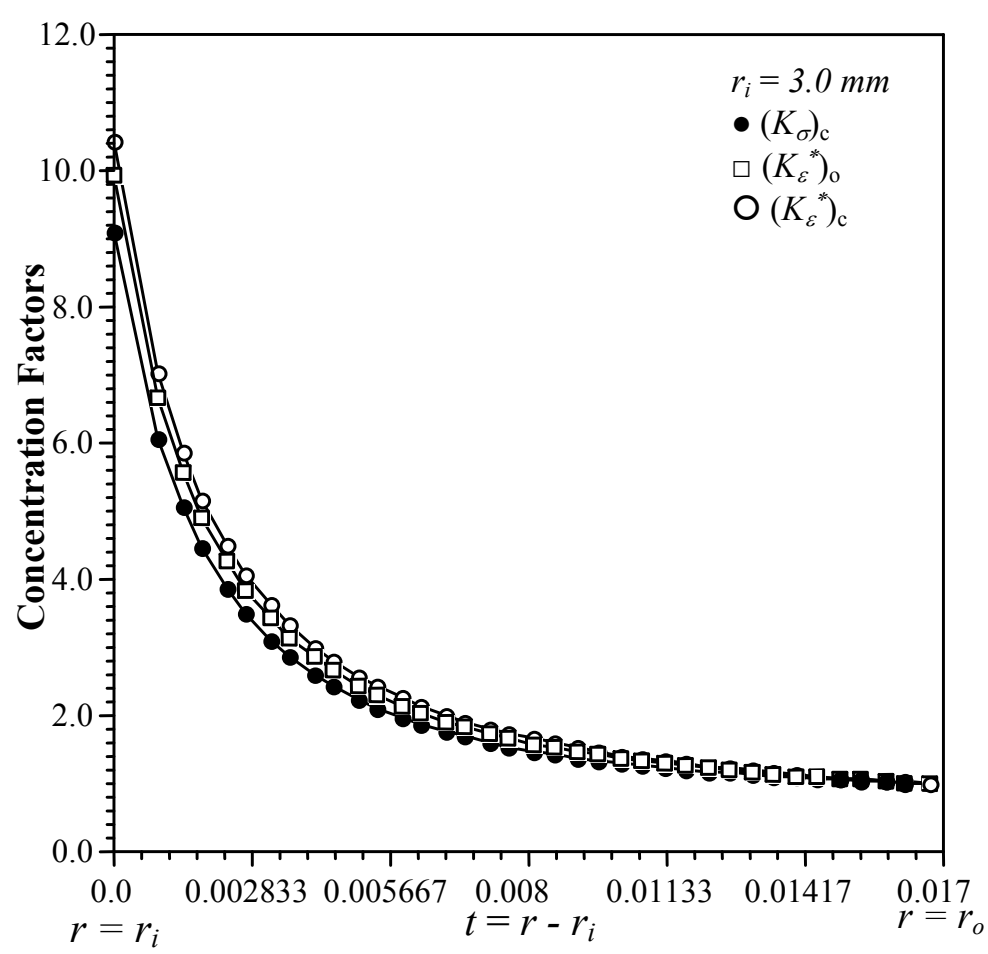

Fig.9. The variation of concentration factors with thickness for $r_{i}=3.0 \mathrm{~mm}$.

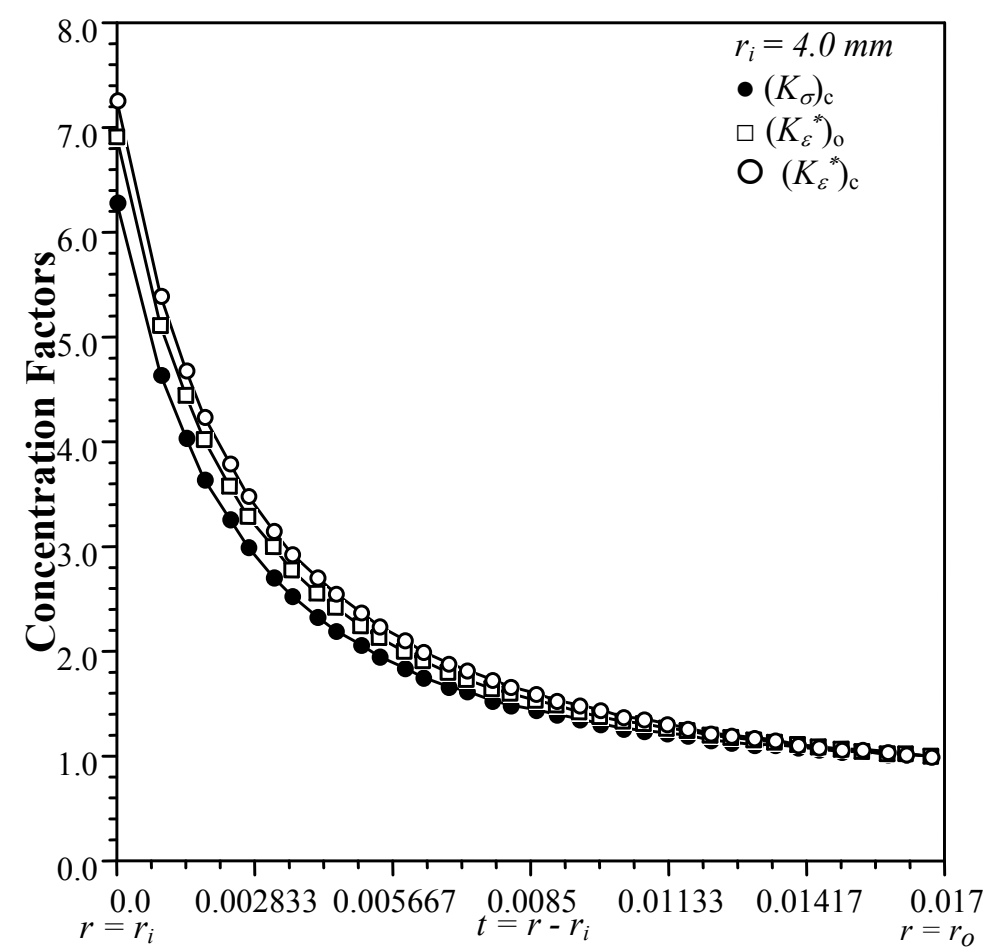

Fig.10. The variation of concentration factors with thickness for $r_{i}=4.0 \mathrm{~mm}$. 


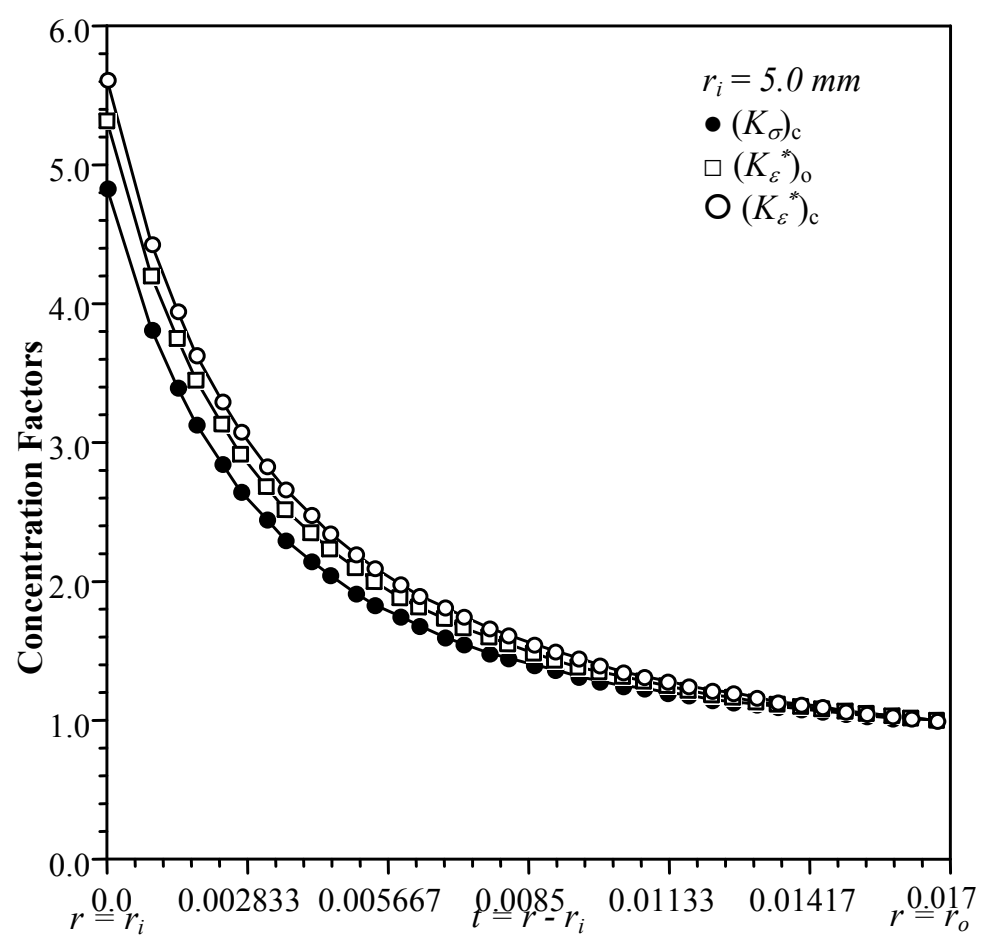

Fig.11. The variation of concentration factors with thickness for $r_{i}=5.0 \mathrm{~mm}$.

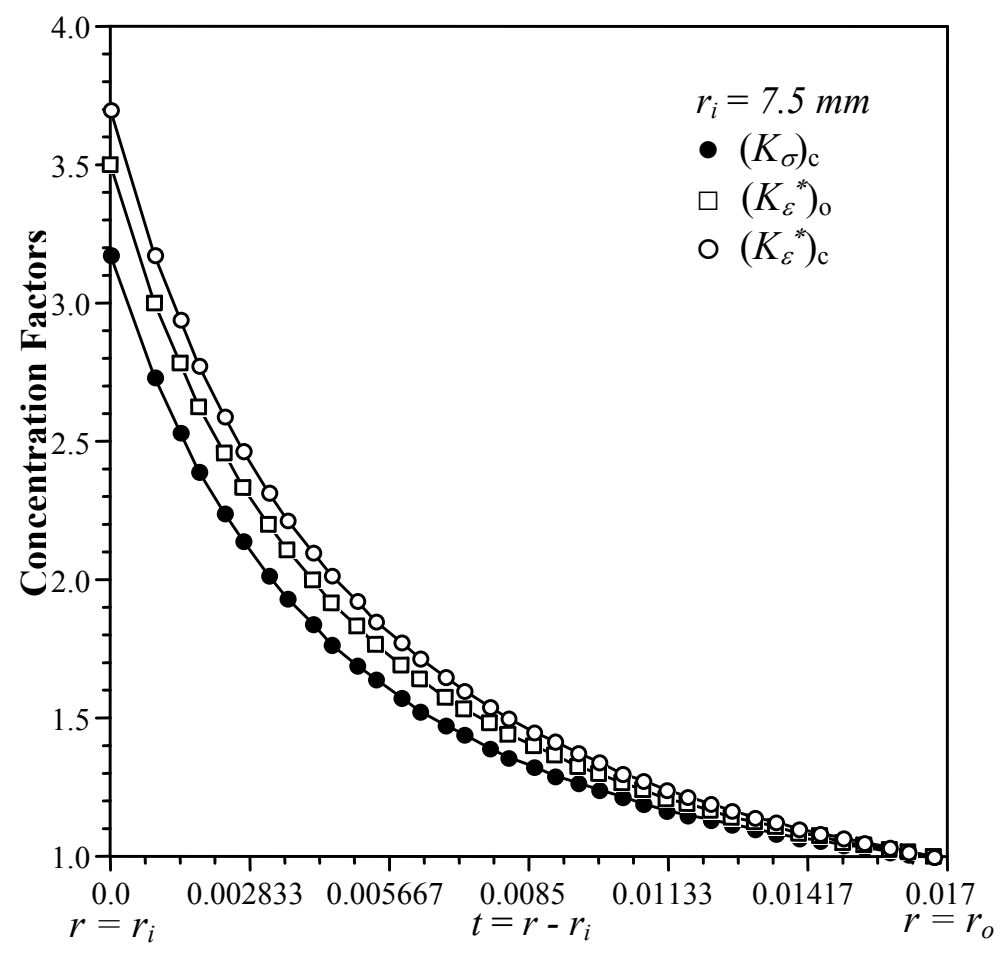

Fig.12. The variation of concentration factors with thickness for $r_{i}=7.5 \mathrm{~mm}$. 


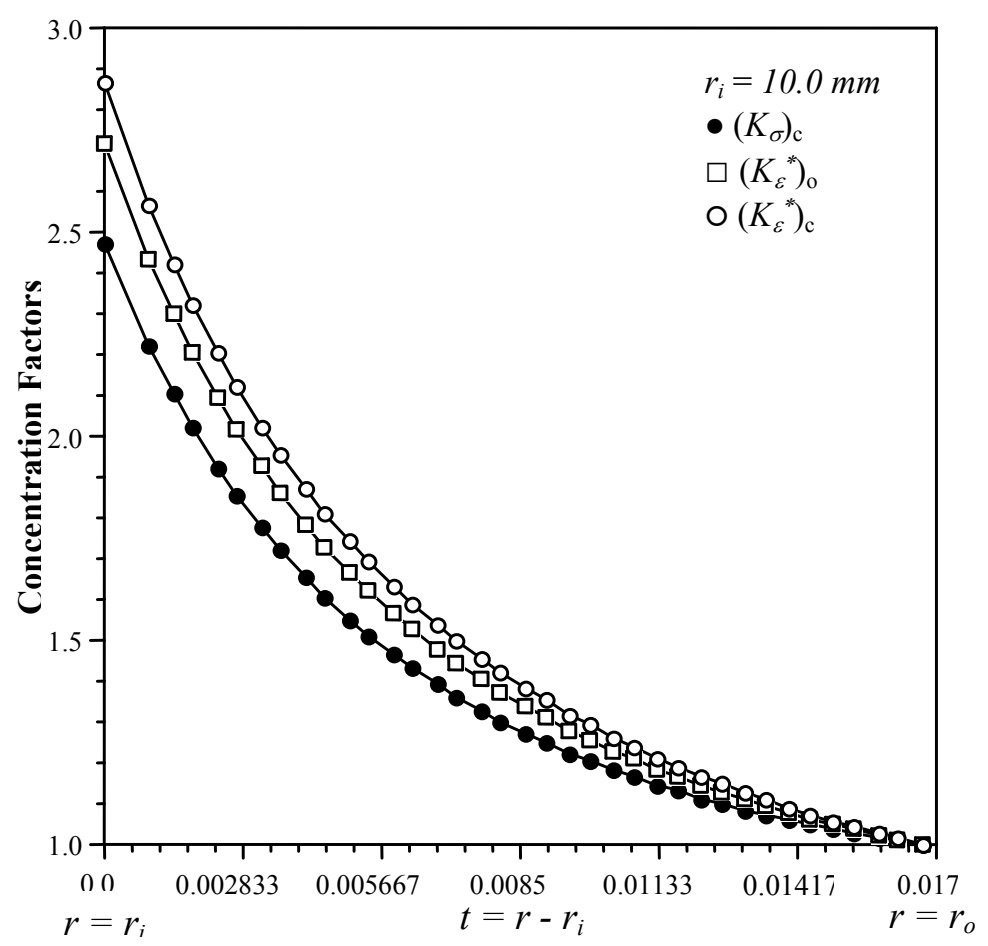

Fig.13. The variation of concentration factors with thickness for $r_{i}=10.0 \mathrm{~mm}$.

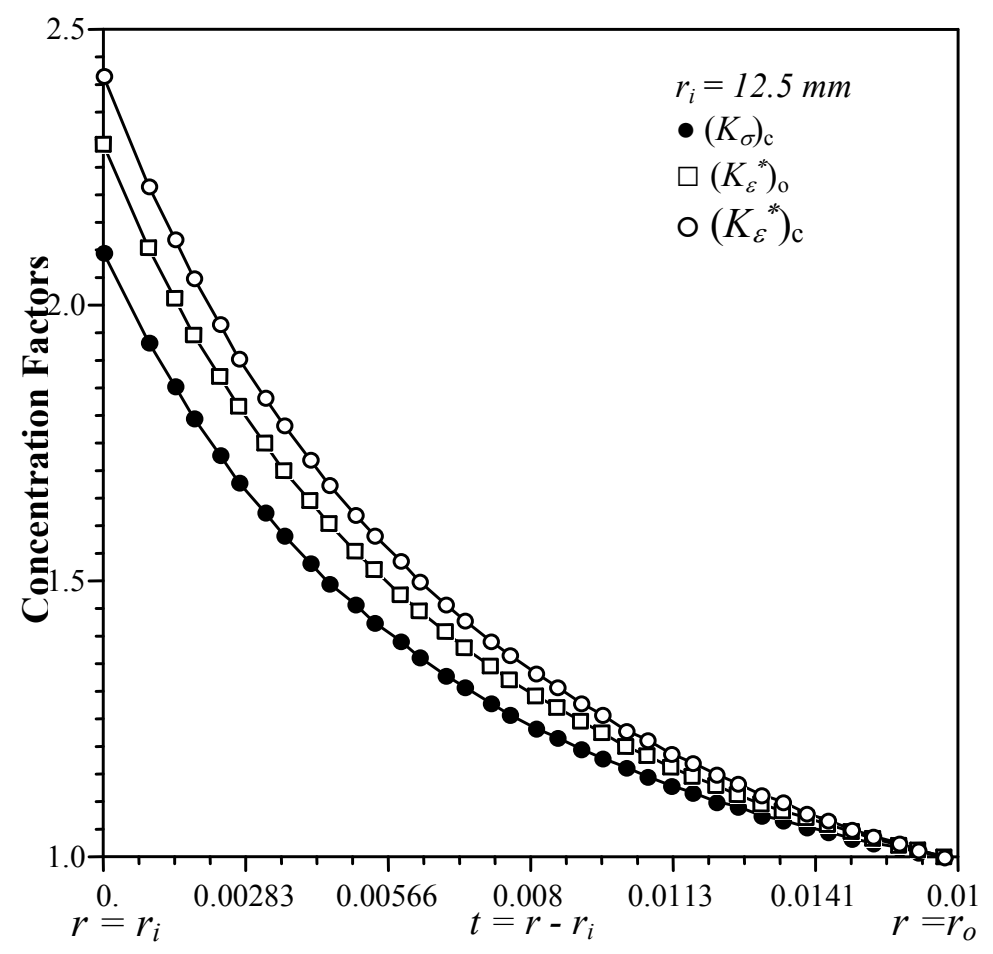

Fig.14. The variation of concentration factors with thickness for $r_{i}=12.5 \mathrm{~mm}$. 


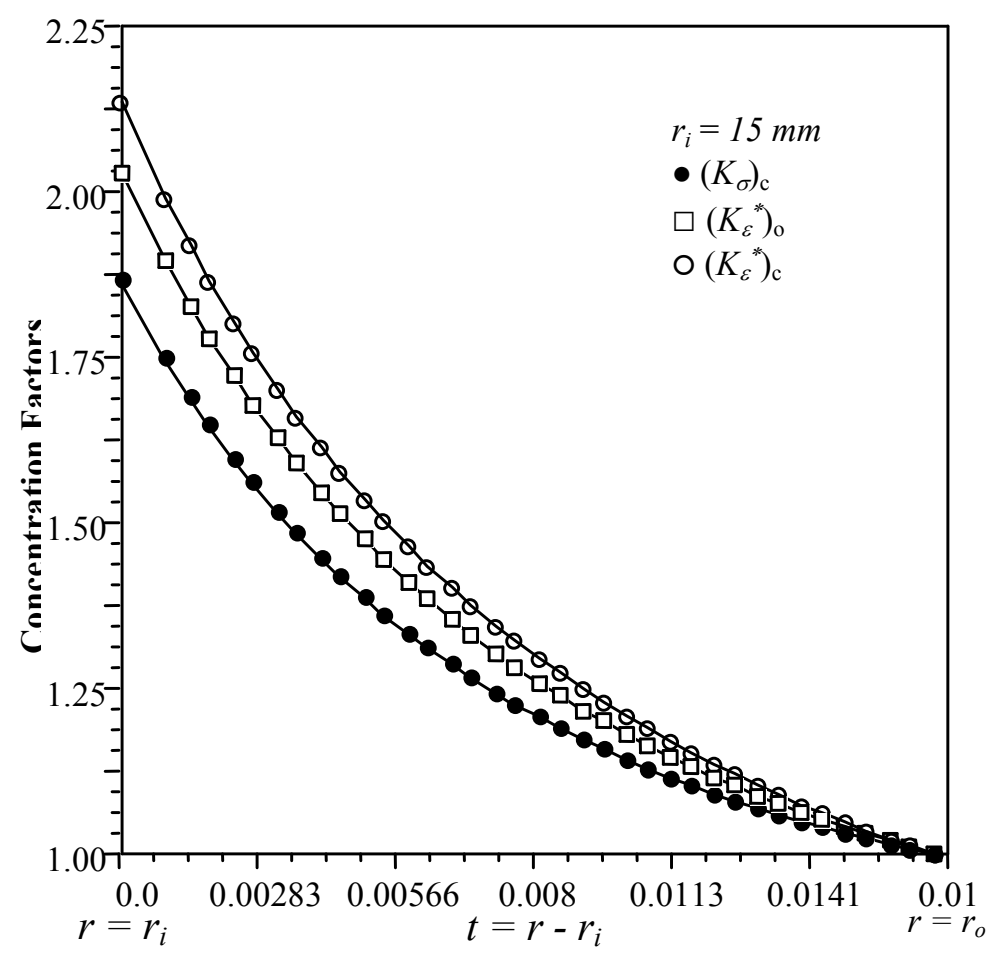

Fig.15. The variation of concentration factors with thickness for $r_{i}=15.0 \mathrm{~mm}$.

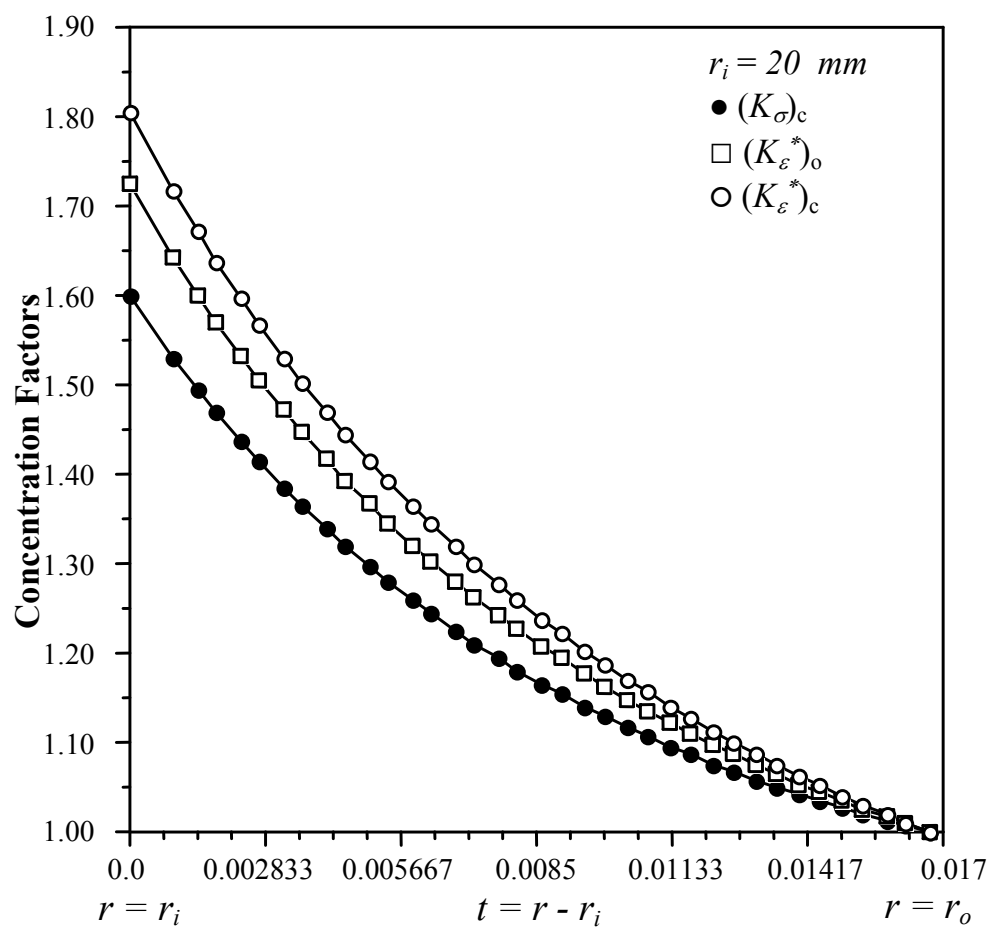

Fig.16. The variation of concentration factors with thickness for $r_{i}=20 \mathrm{~mm}$. 


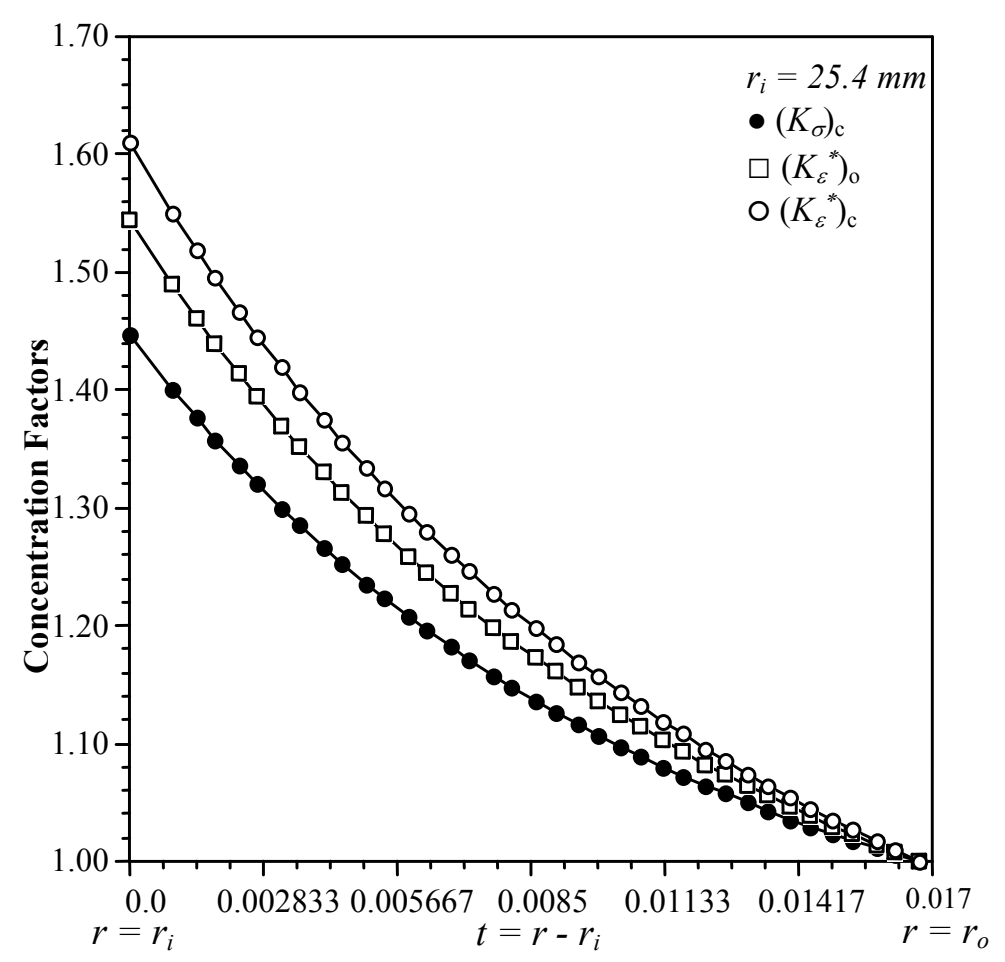

Fig.17. The variation of concentration factors with thickness for $r_{i}=25.4 \mathrm{~mm}$.

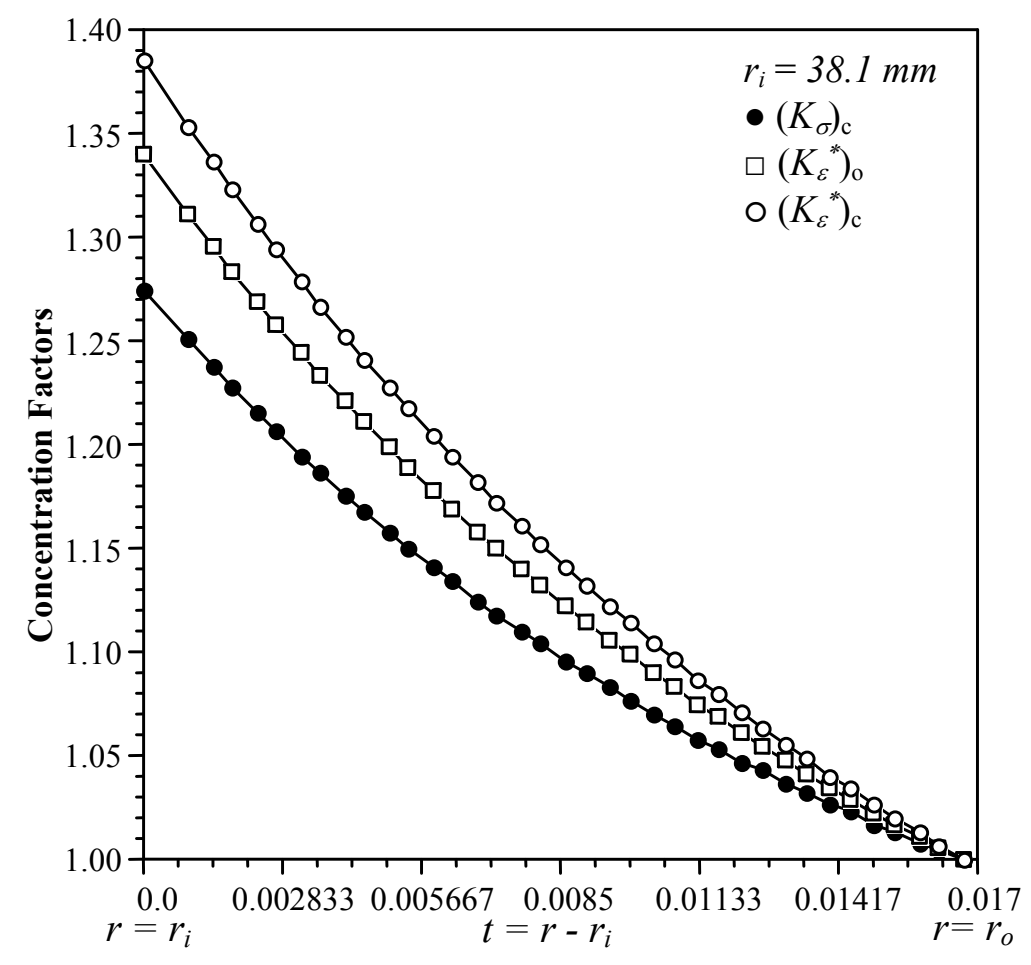

Fig.18. The variation of concentration factors with thickness for $r_{i}=38.1 \mathrm{~mm}$. 


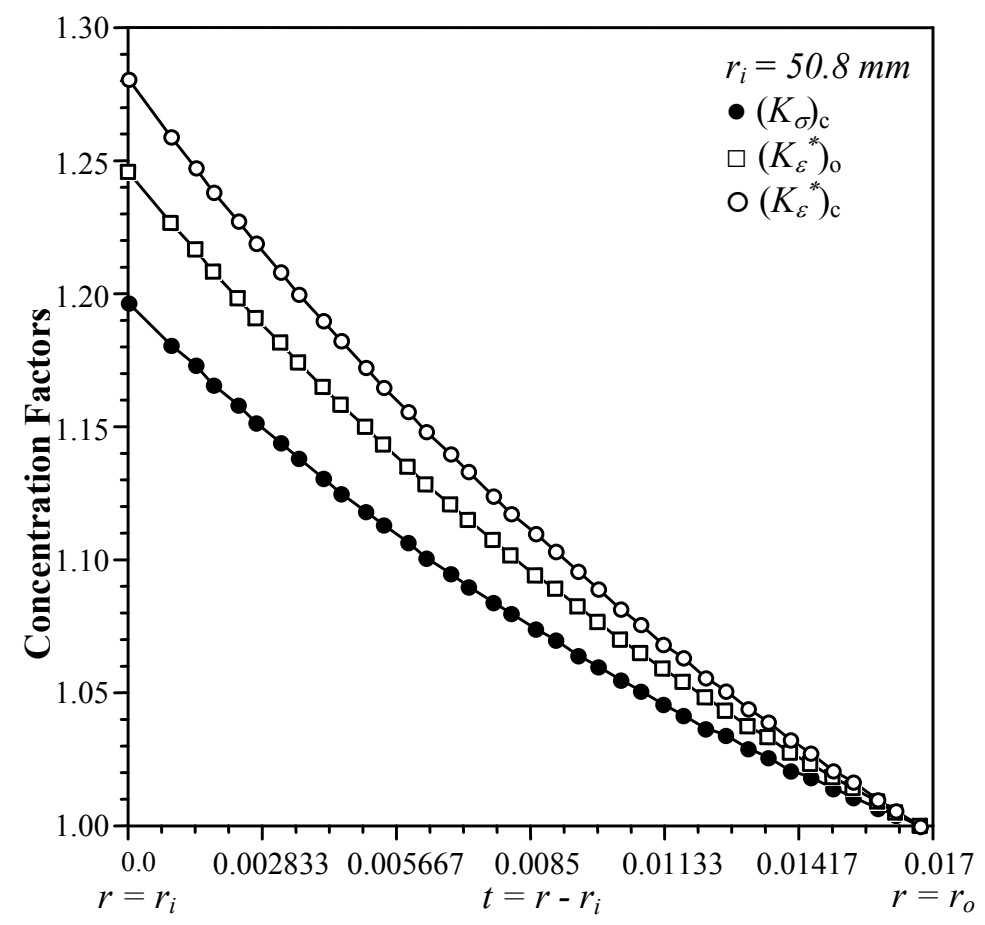

Fig.19. The variation of concentration factors with thickness for $r_{i}=25.4 \mathrm{~mm}$.

\section{Conclusions}

The effect of curvature on the new Strain-Concentration Factor (SNCF) has been studied. The following conclusions are drawn:

1. The new (SNCF) introduced here has been defined under triaxial stress state for the closed ends cylinders and under biaxial stress state for open ends cylinders.

2. The curvature of the internally pressurized cylinders has a prominent effect on the new SNCF as well as on the stress concentration factor.

3. The minimum inner radius of the cylinder leads to the maximum SNCF.

4. The values of the new SNCF are greater than those of the stress concentration factor for all cylinders employed. As the inner radius increases the difference between the SNCF and stress concentration factor becomes more prominent.

\section{Nomenclature}

$$
\begin{aligned}
A & - \text { cross-section area } \\
\mathrm{E} & - \text { Young's modulus } \\
K_{\varepsilon}^{*} & - \text { new strain-concentration factor } \\
\left(K_{\varepsilon}^{\text {new }}\right)_{\text {closed }} & \text {-new strain-concentration factor for closed ends cylinder; }\left(K_{\varepsilon}^{\text {new }}\right)_{c} \\
\left(K_{\varepsilon}^{\text {new }}\right)_{\text {open }} & - \text { new strain-concentration factor for open ends cylinder; }\left(K_{\varepsilon}^{\text {new }}\right)_{o} \\
\left(K_{\sigma}\right)_{c} & - \text { stress-concentration factor for closed ends cylinder } \\
P_{i} & - \text { internal pressure } \\
P_{o} & - \text { external pressure }
\end{aligned}
$$




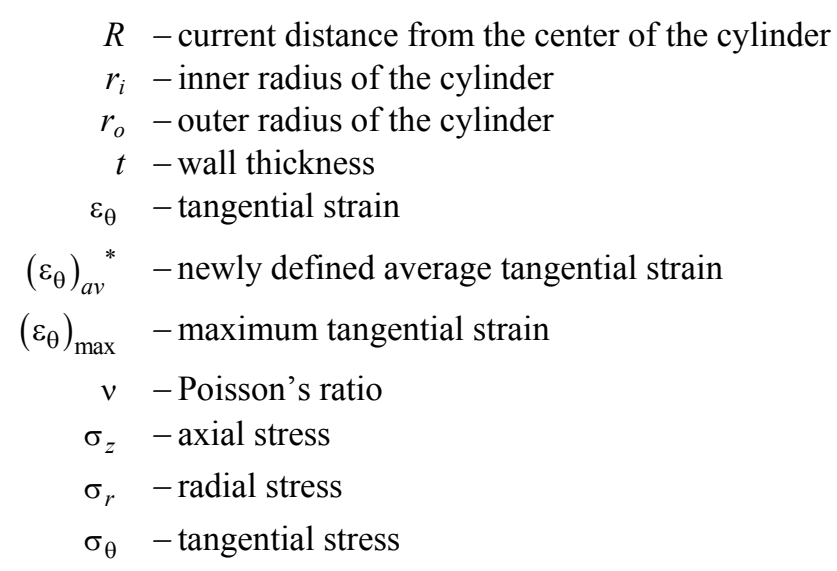

\section{References}

[1] Hill R. (1950): The mathematical theory of plasticity. - Oxford: Clarendon Press.

[2] Nadai A. (1950): Theory of flow and fracture of solids. - New York: McGraw Hill.

[3] Kaufman A. and Spera D. (1965): Investigation of the elastic-plastic stress state around reinforced opening in a spherical shell. - NASA Scientific and Technical Publications, pp.1-27.

[4] Calladine C.R. (1966): On the design of reinforcement for openings and nozzles in thin spherical pressure vessels. Journal Mechanical Engineering Science, vol.8, pp.1-14.

[5] Bapu Rao M.N. and Murthy M.V.V. (1971): On the stresses in the vicinity of an elliptic hole in a cylindrical shell under torsional loading. - Nuclear Engineering and Design, vol.16, pp.309-321.

[6] Iyer M.S. (1975): Analysis of a pressure vessel junction by the finite element method. - Texas Tech University, pp.1-159.

[7] Durban D. and Kubi M. (1992): A general solution for the pressurized elastoplastic tubes. - ASME J. Appl. Mech., vol.59, pp.20-26.

[8] Kihiul J.M. and Masu L.M. (1995): The effect of chamfer and size on the stress distributions in a thick-walled cylinder with a cross bore under internal pressure. - R and D Journal, pp.73-78.

[9] Magnucki K., Szyc W. and Lewiński J. (2002): Minimization of stress concentration factor in cylindrical pressure vessels with ellipsoidal heads. - Int. J. Pressure Vessels and Piping, vol.79, pp.841-846.

[10] Schindler S. (2003): Stress concentration factors of nozzle-sphere connections. - Int. J. Pressure Vessels and Piping, vol.80, pp.87-95.

[11] Fuad Kh. (2007): Stress Concentration Factors of Various Adjacent Holes Configurations in a Spherical Pressure Vessel. - ACAM.

[12] Snowberger D. (2008): Stress concentration factor convergence comparison study of a flat plate under elastic loading conditions. - Rensselaer Polytechnic Institute Hartford, Connecticut December.

[13] Jahed H. and Dubey R.N. (1997): An axisymmetric method of elastic-plastic analysis capable of predicting residual stress field. - ASME J. Pressure Vessel Technol., vol.119, pp.264-273.

[14] Dubey R.N., Seshadri R. and Bedi S. (2000): Analysis of Thick Elastic - Plastic Cylinders. - Plasticity Conference in Whistler, B.C., Canada.

[15] Parker A.P. (2001): Autofrettage of open end tubes-pressures, stresses, strains and code comparisons. - ASME J. Pressure Vessel Technol., vol.123, pp.271-281. 
[16] Zhao W., Dubey R.N. and Seshadri R. (2001): A simplified method for estimating residual stresses fields in elasticplastic thick-walled cylinder subjected to high internal pressure. - 18th Canadian Congress of Applied Mechanics, pp.325-326.

[17] Makulsawatudom P., Mackenzie D. and Hamilton R. (2004): Stress concentration at crossholes in thick cylindrical vessels. - The J. of Strain Analysis for Engg. Design., vol.39, pp.471-481.

[18] You-Hong Liu (2004): Limit pressure and design criterion of cylindrical pressure vessels with nozzles. - Int. J. of Pressure Vessels and Piping, vol.81, pp.619-624.

[19] De Carvalho E.A. (2005): Stress concentration factors for an internally pressurized circular vessel containing a radial U-Notch. - Int. J. of Pressure Vessels and Piping, vol.82, pp.517-521.

[20] Kihiu J.M. (2007): Universal SCFs and optimal chamfering in cross-bored cylinders. - Int. J. of Pressure Vessels and Piping, vol.84, pp.396-404.

[21] Quider M. (2009): SCF analysis of a pressurized vessel-nozzle intersection with wall thining damage. - Int. J. of Pressure Vessels and Piping, vol.86, pp.541-549.

[22] Chakrabarty J. (1987): Theory of Plasticity. - New York: McGraw-Hill.

[23] Gao X.-L. (1992): An exact elasto-plastic solution for an open-ended thick-walled cylinder of a strain-hardening material. - Int. J. of Pressure Vessels and Piping, vol.52, pp.129-144.

[24] Gao X.-L. (2003): Strain gradient plasticity solution for an internally pressurized thick - walled spherical shell of an elastic - plastic material. - Mech. Research Communication, vol.30, pp.411-420.

[25] Gao X.-L. (2003): Elasto-plastic analysis of an internally pressurized thick walled cylinder using a strain gradient plasticity theory. - Int. J. of Solid and Structures, vol.40, pp.6445-6455.

[26] Kharat A. and Kulkarni V.V. (2013): Stress concentration at openings in pressure vessels - a review. - Int. J. of Innovative Research in Science, Engineering and Technology, vol.2, pp.670-678.

[27] Kharat A.R., Kamble S.B., Patil A.V. and Burse I.D. (2016): comparative study of different approaches to estimate SCF in pressure vessel opening. - Int. J. of Mechanical Engineering and Technology (IJMET), vol.7, pp.142-155.

Received: November 15, 2017

Revised: September 8, 2018 